\title{
Acquired Carotid-Jugular Fistula: Its Changing History and Management
}

\author{
Claudio Caldarelli, ${ }^{1}$ Marco Biricotti, ${ }^{2}$ Gabriele Materazzi, ${ }^{2}$ \\ Claudio Spinelli, ${ }^{2}$ and Roberto Spisni ${ }^{2}$ \\ ${ }^{1}$ Department of ENT and Maxillo-Facial Surgery, ASL TO2 Torino Emergenza Nord, Ospedale San Giovanni Bosco, Torino, Italy \\ ${ }^{2}$ Department of Surgery, General Surgery 2, University School of Medicine, Ospedali Riuniti di S. Chiara, Pisa, Italy
}

Correspondence should be addressed to Claudio Caldarelli; claudio.caldarelli@fastwebnet.it

Received 2 April 2013; Accepted 27 April 2013

Academic Editors: D. Sander, P. Schoenhagen, and Y. Tohno

Copyright (C) 2013 Claudio Caldarelli et al. This is an open access article distributed under the Creative Commons Attribution License, which permits unrestricted use, distribution, and reproduction in any medium, provided the original work is properly cited.

\begin{abstract}
Purpose. To highlight the changes that have come about in recent years in the etiology, diagnosis, and treatment of acquired carotidjugular fistulas. Methods. We present a review of the literature on acquired carotid-jugular fistulas (CJFs), which includes studies from World Wars I and II up to today and a retrospective analysis of the lesion reports published in the period 2000-2012, with an update of Talwar's table. The case study of one patient suffering from an untreated, long-standing CJF recently treated by us is also presented and included in the updated table. Results. Thanks to early treatment of acute lesions by reconstructive and endovascular surgery, incidence of posttraumatic carotid-jugular fistulas is decreasing, while the number of iatrogenic ones due to medical advances is concomitantly increasing, specifically because of the ever more widespread use of central venous catheters for venous pressure monitoring, parenteral nutrition, and hemodialysis. Conclusion. Although such lesions seem destined to diminish in the future thanks to the above-mentioned diagnostic and therapeutic advances, the increasing number of internal jugular vein catheterizations performed worldwide implies that physicians will still be dealing with carotid-jugular fistulas for many years to come.
\end{abstract}

\section{Introduction and General Considerations}

Arteriovenous fistulas (AVFs) can be either congenital or acquired. Congenital AVFs are less common and frequently have numerous small arteriovenous connections, while acquired fistulas consist of a single larger connection, and they are most frequently the result of penetrating trauma or iatrogenic action (IJV catheter placements). Acquired AVFs have often traumatic origin, and war and after-war periods have offered the major contribution to their knowledge [1-6]. These lesions can involve all the body districts arteries with prevalence in lower extremities (49\%). Superior members localizations follow for $16-26 \%$, head and neck for 3 and $29 \%$, respectively, and chest for 2-3\% [7, 8]. Acquired AVFs involving major vessels in the head and neck are most frequently caused by penetrating trauma (gunshot injury and stab wounds) or by internal jugular vein catheterization for central venous pressure monitoring, parenteral nutrition or vascular access for hemodialysis, nowadays increasing in the developing countries [9].

The epidemiology of traumatic, noniatrogenic carotidjugular fistulas (CJFs) depends on the varying incidence of cervical vascular trauma which was $10.7 \%$ of all injuries in WW I, $0.4 \%$ in WW II, 3.6\% in the Korean War, and 5\% in Vietnam [3, 8]. The different incidences are related to the frequency of stab wounds, which was high in the First World War, rare in the Second, while it increased once again during the Korean and Vietnam Wars due to guerilla warfare. In the most recent case studies regarding the Libyan and Croatian Civil Wars, neck vascular traumas were present in $6.9 \%$ and $6.4 \%$ of all injuries, while in the conflict in Somalia the figure reached $19 \%$. About incidence, the first authors with significant experience (Hughes and Jahnke [2], Beall et al. [3], Rich et al. [6], and Vollmar [8]) reported in their series of traumatic AVFs a percentage of carotid-jugular localizations, respectively of $6.7 \%, 10 \%, 4.3 \%$, and $7 \%$. 
Signs and symptoms of an AVF include pulsatile neck swelling, systolic murmur, palpable thrill, and dilated superficial veins. This is the result of hemodynamic alteration caused by sudden diversion of blood flow from the arterial circuit into the venous one. Physiologic effects of this rearrangement of blood flow are affected by general factors, such as concomitance of preexisting cardiac diseases and factors related to fistula itself, such as its size, the volume of flow through it, the calibre of the vessel involved, and the proximity to the heart. The arteriovenous shunt results in sudden increase of venous return, pressure, and volume, with simultaneous fall in total peripheral resistance: heart rate, stroke volume, cardiac output, and cardiac work immediately increase too as a physiologic response to the overload, and the course is towards irreversible hyperdynamic cardiac failure. Occasionally, a wide pulse pressure is present with low diastolic pressure. The Nicoladoni-Branham sign is present when manual compression of the fistula elicits bradycardia and increases mean arterial pressure. Large AVFs cause increased cardiac output, while heart failure is a rare and late presentation of large, undiagnosed AVFs.

Catheter angiography is still the gold standard for diagnosis, and it offers the possibility of concurrent endovascular treatment. CJFs manifest as early visualization of the draining jugular vein in the arterial phase on conventional angiography. US is a sensitive and noninvasive modality for detecting AVFs. Color and duplex US findings include turbulent IJV flow, increased velocity and low pulsatility carotid flow, increased velocity and high pulsatility IJ flow, and change in calibre of the carotid around the AVF and focal IJV dilation caudal to the AVF. Color Doppler US is very sensitive for visualizing AVFs and may be the reference standard, but it overestimates the diameter of the tract. Other modalities include CT angiography (CTA) and MR angiography (MRA). CTA provides the best spatial resolution of catheter angiography and offers the best three-dimensional localization of the AVF within the tissues if surgical repair is planned. MRA offers flow information via dynamic sequences and phase velocity mapping, though hemodynamic information is inferior to US. MRA spatial resolution is good though inferior to CTA.

The treatment of CJFs consists of eliminating the fistula and reconstructing the involved arteries and veins. When reconstruction is impossible, an alternative approach is ligation of all the contributing vessels leading to and from the fistula. Endovascular treatment by stent grafts and coils is gaining favour today. A significantly lower mortality rate associated with endovascular carotid repair versus the open surgical option is reported, but no case series or long term follow-up studies have compared the treatments. CJFs should always be diagnosed and treated early as untreated may lead to complications as infection, systemic embolization, and congestive heart failure. The recent management of a case of posttraumatic CJF, with very late time of presentation, gave us the starting point to review the literature on this lesion.

To this aim, we considered reports on the acquired traumatic and iatrogenic CJFs published in the period from Word War II up today. The study included the lesions involving
CCA, ICA, ECA, and IJV. Congenital AVFs, vertebral AVFs, cavernous sinus and parotid region AV fistulas, and arteriovenous aneurysms were excluded. Successively, we made a retrospective analysis of lesions published from 2000 to 2012 as sporadic observations. Then, we have focused our attention on the period 1994-2012 differentiating them in two tracts: the 1994-1999 (six years), analyzed by Talwar, and the 20002012 (twelve years) analyzed by us. The study considered causes, diagnosis, treatment of CJFs, and especially their relative incidence in the two selected periods. The research motors were Google and Pub Med.

\section{Literature Review}

The earliest observations of arteriovenous fistulas were made by Hunter in 1757 published in 1764 [10], followed by other descriptions by Osler in 1893 [11], Matas in 1922 [12], Reid in 1925 [13], Holman in 1937 [14], and King in 1943 [15]. However, the very first observation of posttraumatic carotidjugular fistula was published by Warren and colleagues in 1951 [16]. These authors studied the cardiac output in WW II wounded patients with traumatic AVFs and aneurysms. The second report, this one on Korean War wounded patients, was published in 1952 by Seeley and colleagues [1], who suggested that the continuity of major vessels should be re-established by direct anastomosis, homologous artery, or autogenous vein grafts. The third report on AVFs involving cervical arteries and veins was by Hughes and Jahnke, 1958 [2], who published a follow-up study of 215 traumatic AVFs and aneurysms in patients submitted to surgery in the Korean War reporting 7 carotid-jugular fistulas (6.7\% of all 60 AVFs encountered). They recommended simultaneous venous repair in peripheral AVF to prevent swelling of the distal extremity. Another report on the surgical treatment of traumatic arteriovenous aneurysms was later published by Beall and coworkers [3], who in 1963 reported on an unknown number of carotidjugular fistulas (however the $10 \%$ of all AVFs observed) and emphasized the need for immediate repair of the vessels with reestablishment of continuity. These innovative surgeons clearly demonstrated the superiority of reconstructive surgery over the technique employed up to then which was fistula excision with quadruple ligation (ligation of the arteries and veins leading to and from the fistula) [17]. Thus, by the time of the Korean conflict, reconstructive surgery became the rule $[1,2,18,19]$.

In 1964, Holmes [20] performed the first study on circulatory dynamics in the presence of a carotid-jugular fistula, while in 1965 Pate and coworkers [21] reported on 14 cases of cardiac failure following traumatic AVF. The first extensive review of the literature was made by Vollmar and Kranshaar [22], who in 1968 reported on 200 traumatic AVFs: $7 \%$ of all the AVFs reported were carotid-jugular fistulas that occurred during the WW II period. A second wide-ranging review on traumatic AVFs and false aneurysms came from Rich and coworkers [6] who in 1975 identified and studied 11 carotid-jugular fistulas representing $4.3 \%$ of the 262 AVFs encountered amongst 558 vascular injuries in Vietnam War wounded patients. In 1976 Ortiz et al. [23] reported the first 
AVF localized between the inferior thyroid artery and IJV, secondary to IJV catheter placement.

In 1979 Kakkar and coworkers [24] published a case study of a patient who, after multiple hospitalizations for congestive heart failure, underwent surgery for ligature of a large CJF. After the procedure, all signs of congestive heart failure disappeared, and the heart size decreased dramatically. The authors concluded that hemodynamic effects are important sequelae of AVFs and confirmed the 1937 studies of Holman [14], who showed that the degree of arteriovenous shunting depends on the site, size, and distensibility of the fistula. Afterwards, the Spanish literature contains the 1984 study by Dallo et al. [25] who analyzed 33 cases of acquired carotid-jugular fistulas seen between 1945 and 1981 and concluded that signs of fistular cardiopathy and heart failure may become evident from 4 days up to 31 years after the initial insult, stating that the length of the time gap is related to the size of the arteriovenous duct. Moreover Dallo concluded that the size of the arteriovenous duct depends on the distensibility of the communicating ring and that the onset of heart failure depends on the size of the shunt. In 1988, Robinson and Errett [26] published another case report on a CJF that occurred after IJV cannulation with unknown repair.

The most recent review on acquired CJFs has come from Talwar and coworker [27], who in 2000 described a fistula between the proximal left ICA and the IJV treated by institution of a cardiopulmonary bypass and IJV and carotid repair. The authors include a table of reported cases of acquired carotid-jugular fistulas from 1994 up to 2000, which includes the observations of Gobeil et al. (1994) [28], Al-Kutoubi and Kreel (1994) [29], El-Shahawy and Khilnani (1995) [30], Nandapelan et al. (1995) [31], Chen et al. (1995) [32], Nemzek et al. (1996) [33], Huart et al. (1996) [34], and Avrahami et al. (1997) [35]. Two further cases from before 2000, not reported by Talwar, were seen in the Croatian War by Kaklikkaya et al. (1999) [36] and Zakhariev et al. (1999) [37].

Subsequent to Talwar's review, further cases of carotidjugular fistulas have been reported in the literature by Ezri et al. (2001) [38] and Droll and coworkers (2004) [39], who reported on a case of common carotid-jugular vein fistula following the insertion of a double lumen catheter for hemodialysis access. This was the fourth case after Ortiz's first observation in 1976 [24], and three similar cases were later reported in the literature. Droll stressed iatrogenic fistula as a potentially serious complication of IJV catheter insertion and made some recommendations for prevention (ultrasoundguided cannulation, inserting smaller gauge needles to locate the vein before using the larger needles for catheterization) and for early detection of the lesion (auscultation and palpation of suspected sites, duplex scanning, and angiography).

More recently, Hazinedaroglu et al. (2004) [40], Vera et al. (2005) [41], Ezemba et al. (2006) [42], Bawazeer et al. (2006) [43], Kaitzis et al. (2006) [44], and Sharma et al. (2006) [45] have published other case studies of CJF. The most recent cases were due to traumatic catheterization in patients, including pediatric ones as well, whose treatments required long-term intravenous access (López-Quiñones et al., 2006 [46], Dell'Amore et al., 2009 [47], and Chan et al., 2012 [48]).
In the case described by López-Quiñones, angiography confirmed sonograph findings, and endovascular treatment was performed with a covered stent. Subsequent reports of AVFs between CCA and IJV, submitted to a stent-graft placement have come from Kong et al. (2010) [49], Clevert et al. (2010) [50], Patel et al. (2011) [51], Bahcebasi et al. (2011) [52], and Wadhwa et al. (2012) [53].

Wadhwa also included a limited review of the literature focusing on iatrogenic carotid-jugular fistulas published up to 2011. In 2012, Gong et al. [9] reported on a new case of CCA-IJV fistula and concluded that although few cases of such complication have been reported in the literature, physicians must carefully use all the methods at their disposal to reduce the risk of complications during IJV catheterization (anatomical landmarks, ultrasound guidance, careful preparation, and experience). In 2012, Chan et al. [48] reported on a case occurring after IJV cannulation in a pediatric oncologic patient. Finally, Patel, Chan, and Gong performed open surgical repair in three patients between 2011 and 2012. Table 1 updates Talwar with the above-mentioned cases of acquired carotid-jugular fistulas published from 2000 up to date including our observation.

\section{Case Report}

A 51-year-old man presented to our observation in 2009 with a palpable thrill over a soft swelling in the right lateral cervical region. The man had suffered a stab injury 28 years prior and had no problem until 2009, when he noticed a cervical thrill and swelling. Clinical examination showed ECG signs of left ventricular hypertrophy and diastolic overload. Chest radiography and echocardiography revealed mild cardiomegaly. Neck examination revealed an old, small scar on the inferior right side of the neck and a palpable soft swelling with continuous thrill and systolic bruit, which were maximal in the area of Zone II, from the sternal notch to the angle of the mandible. The thrill disappeared upon compression of the scar area or of the carotid artery. A right carotid arteriogram (Figure 1) revealed a fistulous tract, about $0.5 \mathrm{~cm}$ in diameter and $1.5 \mathrm{~cm}$ in length, between the right common carotid artery and the right internal jugular vein.

Open surgery was performed under general anesthesia and EEG monitoring via a longitudinal neck incision anterior to the sternocleidomastoid muscle. The internal jugular vein was appreciably dilated, up to a diameter of $4 \mathrm{~cm}$, and had a very thin wall. Its aspect was similar to that of a superior vena cava. The facial vein was very dilated as well. Communication between the arterial and venous systems was confirmed to be due to a $0.5 \mathrm{~cm}$ diameter fistulous tract, with venous opening localized in the posterior wall of the facial vein. Compressing this area or common carotid artery caused the thrill to disappear. Systemic heparin (5000 IU) was administrated, and complete clamping of the internal jugular vein and side clamping in the common carotid artery were performed without interrupting the flow. The fistulous track was divided, and the openings in the common carotid artery and in the internal jugular vein were closed with direct 6-0 polypropylene sutures. The thrill disappeared upon palpation 


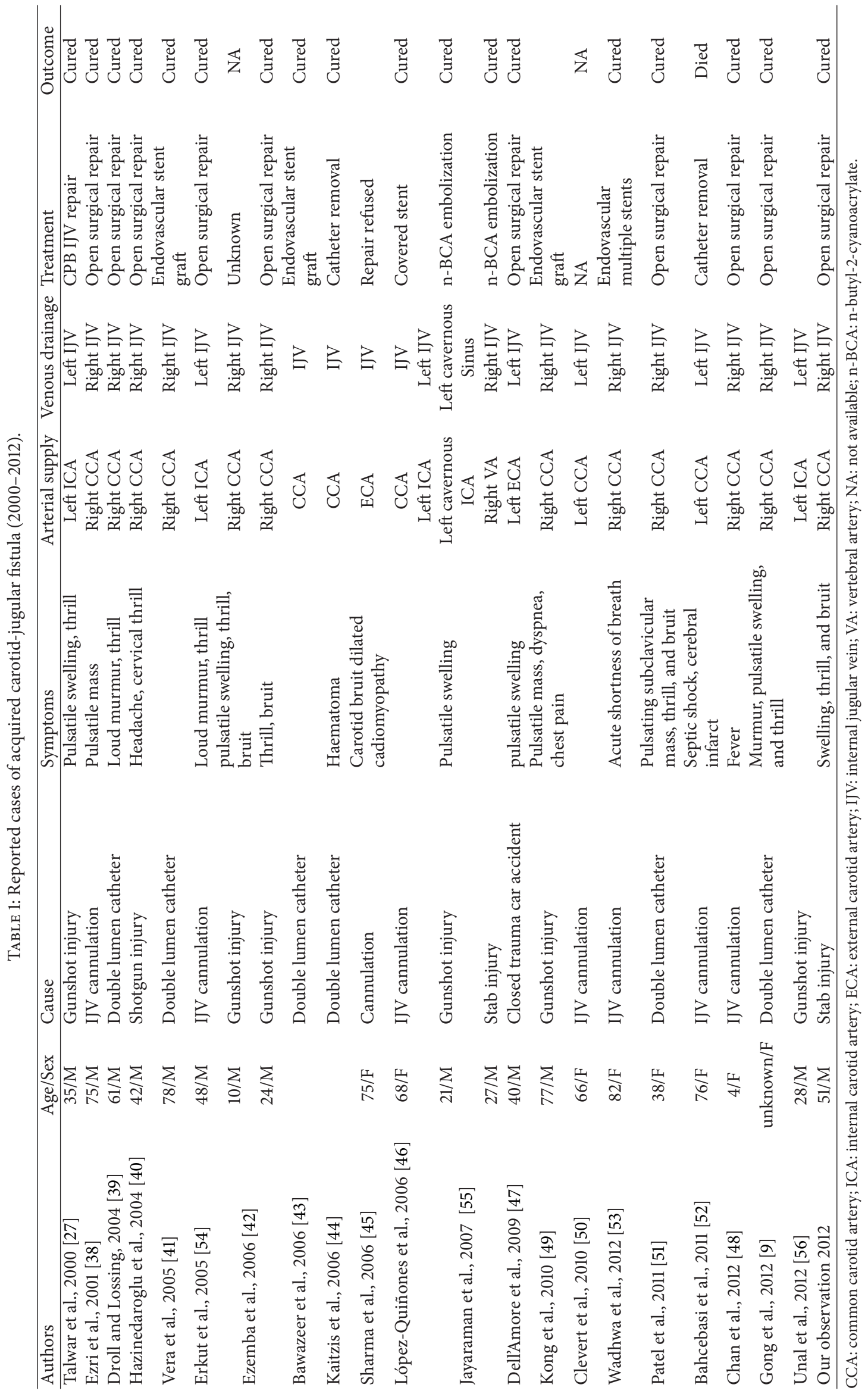




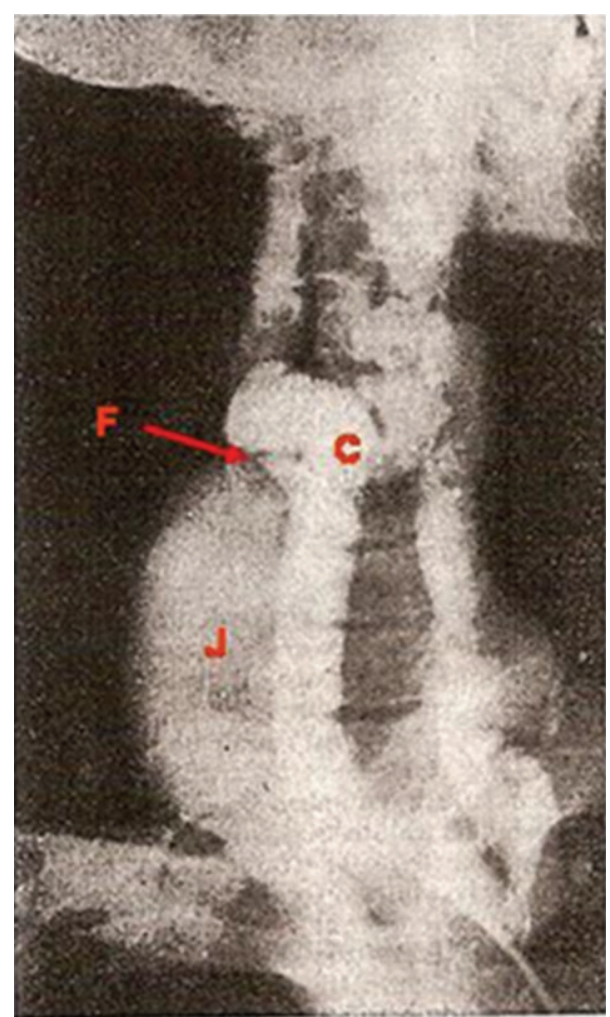

FIGURE 1: Fistulous tract, about $0.5 \mathrm{~cm}$ in diameter and $1.5 \mathrm{~cm}$ in length, between the right common carotid artery and the right internal jugular vein.

of the jugular vein. The patient tolerated the procedure well and was discharged on the third postoperative day. The 30day angiograph control did not reveal any cervical venous vessels in the arterial contrast stage of the exam, and the diameter of the common carotid artery appeared reduced with respect to its preoperative state (Figure 2). During the two-year followup the patient demonstrated improved cardiac performance and a reduction in heart size.

\section{Discussion}

Acquired common carotid-jugular fistulas are uncommon in the head and neck region, accounting only for 4 to $7 \%$ of all the traumatic AVFs encountered throughout the body [41]. They are so rare that they can only be encountered as case reports in the medical literature. Of the 30 cases of CJF reported up to 2000, only 9 were acquired [28], 7 were situated between the CCA and the IJV, and only 2 were between the ICA and the IJV. Apart from 7 cases of CJFs due to gunshot or stab wounds, 3 presented after attempts at jugular catheter insertion [40] or after a long-term catheter indwelling in the jugular vein.

The cases of acquired carotid-jugular fistulas published from 2000 to 2012, included in Table 1, involve 23 patients reported by 21 authors, plus the previously unpublished case described herein, bringing to the overall number to 24 cases reported by 22 authors from 2000 to 2012. Of these, 9 cases

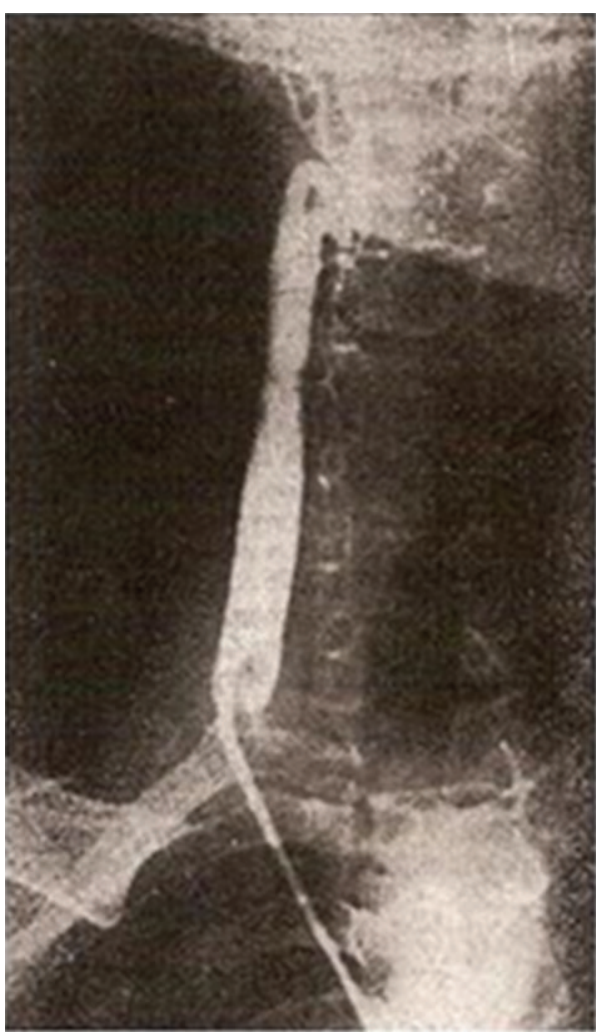

FIgURE 2: The diameter of the common carotid artery appeared reduced with respect to its preoperative state.

were due to gunshot or stab injury, and 14 were due to IJV catheter insertion. Sixteen were between the CCA and IJV, 5 were between the ICA and the IJV, and 2 were between the ECA and the IJV. The treatment performed was open surgical repair in 11 cases and endovascular by covered stent or embolization in 7. A simple catheter removal was made in 2 cases. A patient refused repair. For the remaining cases, neither the cause nor the treatment is available. As the reported incidence of puncture of the carotid artery during IJV catheterization has been estimated between 2\% and 9.9\% [57-59], it seems feasible that the catheter tip may penetrate the vessels walls into the artery following insertion. However, arterial puncture would be the first stage in the development of CJF [9]. As can be seen from Table 1, the cases of acquired CJF published in the period from 2000 to 2012, 24 in 12 years, have been slightly more numerous than those reported between 1994 and 2000 (9 in 6 years) [28], a fact that may indicate an increasing frequency of lesions caused by IJV catheterization.

AVFs following injuries of the neck may go undetected until long after the causative event. A number of cases have been reported which were not treated until several years after the injury. Our patient, together with Kakkar's case, indicates that AVFs may manifest with a time of presentation of up to 29 years from the original injury. However, the longest presentation time recorded in the literature was a patient of Kong's (2010), who was treated by AVF repair 58 years after a gunshot wound. Our case confirms that, 
apart from the time of presentation, hemodynamic signs and symptoms depend also on the fistula characteristics, such as its proximity to the heart, its size, and degree of the leftto-right shunting. Indeed, cases with severe hemodynamic symptoms (high cardiac output and heart failure) present large diameter $(>8 \mathrm{~mm})$ fistulas that allow a large volume of blood to be shunted directly into the venous circulation $[25,41]$. On the other hand, signs and symptoms of smaller diameter arteriovenous fistulas $(<5 \mathrm{~mm})$, with low output, may appear many years after injury and generally consist of mild left ventricular hypertrophy and cardiomegaly without congestive heart failure as in our patient.

If the presence of a AVF is suspected, proper investigation such as duplex scanning and angiography need to be performed to confirm the diagnosis and acquire further data. Although invasive, conventional arteriography offers the most accurate information on the exact site and size of the fistula (Figure 1) and is associated with a relatively low risk of thromboembolic neurological complications. Alternatively, noninvasive methods for detecting AV fistulas include ultrasonography (US) with color Doppler and magnetic resonance angiography (MRA). Color Doppler has gained widespread acceptance in this setting but requires highly trained operators who may not always be available.

The treatment of CJF has progressed greatly since the advent of endovascular surgery. Since 1980, endovascular therapy, using balloon occlusion techniques, has been reported in surgical inaccessible, traumatic carotid, and vertebral AVFs in which the distal vessel was occluded $[60,61]$. Later, endovascular techniques were attempted in AVFs involving the internal carotid artery, cavernous sinus, and parotid region and when the internal carotid artery was involved in neck Zone III, from the mandible angle to the skull base. However, endovascular treatment of carotidjugular AVFs gained widespread acceptance in 2004, when Droll performed percutaneous insertion of a covered stent in a case where the vessel distal to the fistula site was patent and normal arterial flow had to be preserved. Since then, the endovascular procedure has been used by several authors: Ezemba et al., 2005 [42], Kaitzis et al., 2006 [44], López Quiñones et al., 2006 [46], Kong et al., 2010 [49], and Wadhwa et al., 2012 [53].

Nevertheless, whether the approach to treating AVFs should be via open surgery, or endovascular is still a matter of debate [41]. To date, direct repair of AVFs between the common or internal carotid artery and the internal jugular vein seems to be preferred in large sized fistulas consequent to a gunshot or stab wound, or when AVFs are associated with false aneurysms or other vessel wall lesions. Endovascular treatment by stent-graft insertion is preferred in small diameter fistulas, in those occurring during or after IJV catheterization, in those without other associated vascular lesions as well as in patients at high risk for open surgery. However, no case series or long-term follow-up studies have compared the treatments which is still determined on a case-by-case basis. However, the primary indication for such a choice is the fistula site: endovascular techniques have replaced open surgical treatment for vertebral artery fistulas, high carotid-jugular fistulas [55], and, generally, for carotid artery injuries in either Zone I or Zone III where access to vessels is difficult [62].

\section{References}

[1] S. F. Seeley, C. W. Hughes, F. N. Cook, and D. C. Elkin, “Traumatic arteriovenous fistulas and aneurysms in war wounded. A study of 101 cases," The American Journal of Surgery, vol. 83, no. 3, pp. 471-479, 1952.

[2] C. W. Hughes and E. J. Jahnke Jr., "The surgery of traumatic arteriovenous fistulas and aneurysms: a five-year follow up study of 215 lesions," Annals of Surgery, vol. 148, no. 5, pp. 790797, 1958.

[3] A. C. Beall, O. B. Harrington, E. S. Crawford, and M. E. Debakey, "Surgical management of traumatic arteriovenous aneurysms," The American Journal of Surgery, vol. 106, no. 4, pp. 610-618, 1963.

[4] T. J. Whelan, W. E. Burkhalter, and A. Gomez, "Management of war wounds," Advances in Surgery, vol. 3, p. 327, 1968.

[5] R. L. Hewitt and D. J. Collins, "Acute arteriovenous fistulas in war injuries," Annals of Surgery, vol. 169, no. 3, pp. 447-449, 1969.

[6] N. M. Rich, R. W. Hobson, and G. J. Collins, "Traumatic arteriovenous fistulas and false aneurysms: a review of 558 lesions," Surgery, vol. 78, no. 6, pp. 817-828, 1975.

[7] G. Heberer and G. Rau, "Gefasserzat bei traumatischen arteriovenosen Fisteln mit vaskularer dekompensation Laugenbecks," Archiv fur Klinische Chirurgie, vol. 299, p. 254, 1962.

[8] J. Vollmar, Rekonstruktive Chirurgie der Arterien, Georg Thieme, 1967.

[9] Y. Gong, H. X. Xu, M. Lin, and Y. Gu, "An iatrogenic complication of internal jugular vein catheterization for hemodialysis," Irish Journal of Medical Sciences, vol. 181, pp. 135-137, 2012.

[10] W. Hunter, "Further observations upon a particular species of aneurysm," Medical Observations and Inquiries, vol. 2, p. 390, 1764.

[11] W. Osler, "Case of arteriovenous aneurysm of the axillary artery and vein of 14 years duration," Annals of Surgery, vol. 17, p. 37, 1893.

[12] R. Matas, "Arteriovenous fistula," Surgical Clinics of North America, vol. 2, p. 1165, 1922.

[13] M. R. Reid, "Studies on abnormal arteriovenous complications acquired and congenital. I. Report of a series of cases," Archives of Surgery, vol. 10, p. 601, 1925.

[14] E. Holman, Arterio Venous Aneurysm: Abnormal Communications between the Arterial and Venous Circulations, Macmillan, New York, NY, USA, 1937.

[15] E. S. J. King, "Arterio-venous, (carotid-jugular) fistula and carotid aneurysm," Australian and New Zealand Journal of Surgery, vol. 12, pp. 285-288, 1943.

[16] J. V. Warren, J. L. Nickerson, and D. C. Elkin, "The cardiac output in patients with arteriovenous fistulas," The Journal of Clinical Investigation, vol. 30, no. 2, pp. 210-214, 1951.

[17] D. C. Elkin and H. B. Shumacker, "Arterial aneurysms and arteriovenous fistula," in Surgery in World War II, Vascular Surgery, D. C. Elkin and M. E. De Bakey, Eds., Office of the Surgeon General, Department of the Army, 1955.

[18] N. M. Rich, J. H. Bangh, and C. W. Hugues, "Arterial injury in Viet Nam: 1000 cases," The Journal of Trauma, vol. 10, pp. 359369, 1970. 
[19] E. J. Jahnke and J. M. Howard, "Primary repair of major arterial injuries; report of fifty-eight casualties," A.M.A. Archives of Surgery, vol. 66, no. 5, pp. 646-649, 1953.

[20] T. W. Holmes, "Circulatory dynamics in the presence of the carotid-jugular fistula," Circulation, vol. 29, pp. 905-910, 1964.

[21] J. W. Pate, R. T. Sherman, T. Jackson, and H. Wilson, "Cardiac failure following traumatic arteriovenous fistula. A report of 14 cases," The Journal of trauma, vol. 29, pp. 398-403, 1965.

[22] J. Vollmar and D. Kranshaar, "Surgical experience with 200 traumatic arterial lesions," in Traumatic Arterial Lesions, T. X. Houston and B. Rybeck, Eds., Stockholm, Sweden, 1968.

[23] J. Ortiz, G. L. Zumbro, W. F. Dean, and R. L. Treasure, "Arteriovenous fistula as a complication of percutaneous internal jugular vein catheterization: case report," Military Medicine, vol. 141, no. 3, p. 171, 1976.

[24] S. Kakkar, P. Angelini, R. Leachman, and D. A. Cooley, "Successful closure of post-traumatic carotid-jugular arteriovenous fistula complicated by congestive heart failure and cerebrovascular insufficiency," Cardiovascular Diseases, vol. 6, no. 4, pp. 457-462, 1979.

[25] L. Dallo, C. Pastrana, G. Rodríguez, O. Medina Mora, R. Barragán, and D. Bialostozky, "Acquired systemic arteriovenous fistulas. Experience of 33 cases," Archivos del Instituto de Cardiologia de Mexico, vol. 54, no. 2, pp. 159-166, 1984.

[26] R. Robinson and L. Errett, "Ateriovenous fistula following percutaneous internal jugular vein cannulation: a report of carotid artery-to-internal jugular vein fistula," Journal of Cardiothoracic Anesthesia, vol. 2, no. 4, pp. 488-491, 1988.

[27] S. Talwar, A. Bhan, R. Sharma, S. K. Choudhary, and P. Venugopal, "Carotid artery-to-jugular vein fistula: repair using cardiopulmonary bypass," Asian Cardiovascular and Thoracic Annals, vol. 8, no. 4, pp. 366-368, 2000.

[28] F. Gobeil, P. Couture, D. Girard, and R. Plante, "Carotid arteryinternal jugular fistula: another complication following pulmonary artery catheterization via the internal jugular venous route," Anesthesiology, vol. 80, no. 1, pp. 230-232, 1994.

[29] M. A. Al-Kutoubi and I. Kreel, "Neck truma," Postgraduate Medical Journal, vol. 70, pp. 367-368, 1994.

[30] M. A. El-Shahawy and H. Khilnani, "Carotid-jugular arteriovenous fistula: a complication of temporary hemodialysis catheter," American Journal of Nephrology, vol. 15, no. 4, pp. 332336, 1995.

[31] V. Nandapelan, D. C. O'Sullivan, M. Siodalk, and P. Charters, "Acute airways obstruction due to ruptured aneurysmal arteriovenous fistula: common carotid artery to internal jugular vein," The Journal of Laryngology \& Otology, vol. 109, pp. 562-564, 1995.

[32] Y. W. Chen, P. K. Yip, B. S. Hwang, J. S. Jeng, and W. H. Lin, "Color Doppler sonographic study of an iatrogenic fistula between the common carotid artery and internal jugular vein," Journal of Ultrasound in Medicine, vol. 14, no. 10, pp. 777-780, 1995.

[33] W. R. Nemzek, S. T. Hecht, P. J. Donald, R. A. McFall, and V. C. Poirier, "Prediction of major vascular injury in patients with gunshot wounds to the neck," American Journal of Neuroradiology, vol. 17, no. 1, pp. 161-167, 1996.

[34] J. Y. Huart, M. Sibe, M. Al Sayed, J. Combe, and G. Camelot, "Carotid-jugular fistula after Greenfield filter insertion," Journal des Maladies Vasculaires, vol. 21, no. 5, pp. 308-311, 1996.

[35] R. Avrahami, M. Levinzon, M. Haddad, and A. Zelikovsky, "Traumatic common carotid-internal jugular fistula: positive aspect," Harefuah, vol. 132, no. 12, pp. 841-911, 1997.
[36] I. Kaklikkaya, F. Özcan, and N. Kutlu, "Double layered autogenous vein graft patch reconstruction of the common carotidinternal jugular fistula caused by gunshot wound," Journal of Cardiovascular Surgery, vol. 40, no. 3, pp. 429-433, 1999.

[37] T. Zakhariev, V. Chervenkov, V. Govedarsky, and A. Chirkov, "Our experience in the diagnosis and treatment of carotidjugular fistulae," Khirurgiia, vol. 55, no. 4, pp. 16-19, 1999.

[38] T. Ezri, P. Szmuk, Y. Cohen et al., "Carotid artery-internal jugular vein fistula: a complication of internal jugular vein catheterization," Journal of Cardiothoracic and Vascular Anesthesia, vol. 15, no. 2, pp. 231-232, 2001.

[39] K. P. Droll and A. G. Lossing, "Carotid-jugular arteriovenous fistula: case report of an iatrogenic complication following internal jugular vein catheterization," Journal of Clinical Anesthesia, vol. 16, no. 2, pp. 127-129, 2004.

[40] S. M. Hazinedaroglu, V. Genc, A. Y. Aksoy, C. Köksoy, A. Tüzüner, and E. Atahan, "A late onset carotido-jugular fistula following shotgun injury," Vasa, vol. 33, no. 1, pp. 46-48, 2004.

[41] M. Vera, L. Quintana, J. Blasco, M. Real, and J. M. Macho, "Treatment with the placement of carotid stent of jugularcarotid fistula after the insertion of hemodialysis catheter," Nefrologia, vol. 25, no. 5, pp. 568-571, 2005.

[42] N. Ezemba, E. E. Ekpe, H. A. Ezike, and C. H. Anyanwu, "Traumatic common carotid-jugular fistula: report of 2 cases," Texas Heart Institute Journal, vol. 33, no. 1, pp. 81-83, 2006.

[43] M. A. Bawazeer, M. S. Al-Jared, K. A. Al-Brekeit, and W. M. Al-Harbi, "The use of endovascular stent-grafts for the treatment of common carotid-internal jugular fistula," Saudi Medical Journal, vol. 27, no. 1, pp. 101-104, 2006.

[44] D. G. Kaitzis, A. G. Balitas, I. K. Skandalos, and A. K. Hatzibaloglou, "Carotid artery repair after erroneous insertion of a hemodialysis catheter: case report," Journal of Vascular Access, vol. 7, no. 3, pp. 136-138, 2006.

[45] V. K. Sharma, A. W. Pereira, B. K. Ong, R. Rathakrishnan, B. P. Chan, and H. L. Teoh, "Images in cardiovascular medicine. External carotid artery-internal jugular vein fistula: a complication of internal jugular cannulation," Circulation, vol. 113, no. 16, pp. e722-e723, 2006.

[46] M. López-Quiñones, X. Bargalló, J. Blasco et al., "Iatrogenic carotid-jugular arteriovenous fistula: color Doppler sonographic findings and treatment with covered stent," Journal of Clinical Ultrasound, vol. 34, no. 6, pp. 301-305, 2006.

[47] A. Dell'Amore, F. Castriota, S. Calvi, D. Magnano, G. Noera, and M. Lamarra, "Post-traumatic carotid-jugular arterio-venous fistula," Heart Lung and Circulation, vol. 18, no. 4, p. 293, 2009.

[48] C. C. Chan, V. Lee, W. Chu, Y. H. Tam, C. K. Li, and M. M. K. Shing, "Carotido-jugular arteriovenous fistula: an unusual complication of internal jugular vein catheterization in children," Pedriat Blood Cancer, vol. 59, pp. 1302-1304, 2012.

[49] J. H. Kong, S. M. Park, T. H. Kim, D. H. Choi, and D. Y. Lee, "Late-onset congestive heart failure in a patient with a 58year-old huge traumatic carotid-jugular fistula and pseudoaneurysm: endovascular treatment with a stent-graft," Annals of Vascular Surgery, vol. 24, no. 7, pp. 955.e5-955.e10, 2010.

[50] D. A. Clevert, C. Kubisch, S. Weckbach, U. Frey, K. Stock, and M. Reiser, "B-flow and color Doppler sonography findings in iatrogenic carotid-jugular arteriovenous fistula," Clinical Hemorheology and Microcirculation, vol. 44, no. 1, pp. 19-25, 2010.

[51] H. V. Patel, V. V. Sainaresh, S. H. Jain et al., "Carotid-jugular arteriovenous fistula: a case report of an iatrogenic complication 
following internal jugular vein catheterization for hemodialysis access," Hemodialysis International, vol. 15, no. 3, pp. 404-406, 2011.

[52] S. Bahcebasi, I. Kocyigit, L. Akyol et al., "Carotid-jugular arteriovenous fistula and cerebrovascular infarct: a case report of an iatrogenic complication following internal jugular vein catheterization," Hemodialysis International, vol. 15, no. 2, pp. 284-287, 2011.

[53] R. Wadhwa, J. Toms, A. Nanda, K. Abreo, and H. Cuellar, “. Angioplasty and stenting of a jugular carotid fistula resulting from the inadvertent placement of a hemodialysis catheter: case report and review of literature," Seminars in Dialysis, vol. 25, no. 4, pp. 460-463, 2012.

[54] B. Erkut, N. Becit, M. A. Kaygin, and Y. Velioglu, "Iatrogenic arteriovenous fistula between the common carotid artery and internal jugular vein: a case report," European Journal of Vascular \& Endovascular Surgery, vol. 30, no. 5, p. 567, 2005.

[55] M. V. Jayaraman, H. M. Do, and M. P. Marks, "Treatment of traumatic cervical arteriovenous fistulas with N-butyl-2cyanoacrylate," American Journal of Neuroradiology, vol. 28, no. 2, pp. 352-354, 2007.

[56] O. Unal, B. Citgez, M. Battal, and O. Karatepe, "Multiple gunshot carotico-jugular fistulas," BMJ Case Reports, 2012.

[57] T. L. K. Rao, A. Y. Wong, and M. R. Salem, "A new approach to percutaneous catheterization of the internal jugular vein," Anesthesiology, vol. 46, no. 5, pp. 362-364, 1977.

[58] J. I. Sznajder, F. R. Zveibil, and H. Bitterman, "Central vein catheterization. Failure and complication rates by three percutaneous approaches," Archives of Internal Medicine, vol. 146, no. 2, pp. 259-261, 1986.

[59] F. E. Weale, "Un introduction to surgical hemodynamics Chap VII: arteriovenous fistula," in Arteriovenous Fistula, pp. 74-78, Lloyd-Luke, London, UK, 1966.

[60] R. T. Higashida, V. V. Halbach, F. Y. Tsai et al., "Interventional neurovascular treatment of traumatic carotid and vertebral artery lesions: results in 234 cases," American Journal of Roentgenology, vol. 153, no. 3, pp. 577-582, 1989.

[61] D. V. Feliciano, "Management of penetrating injuries to carotid artery," World Journal of Surgery, vol. 26, no. 2, p. 284, 2002.

[62] D. S. Sumner, Hemodynamics and Pathophysiology of Arteriovenous Fistulas in RB Rutherford, Vascular Surgery Saunders Company, 1977. 


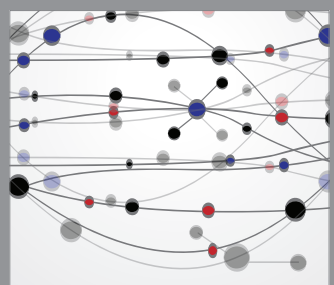

The Scientific World Journal
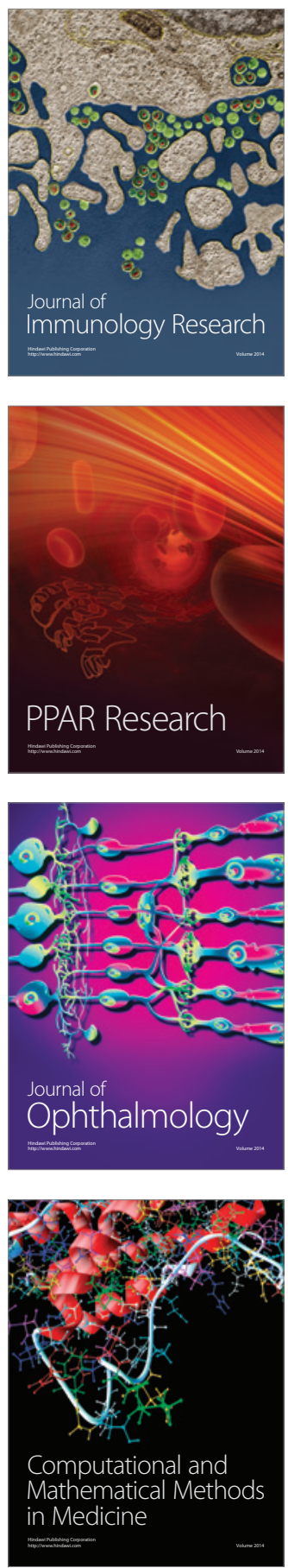

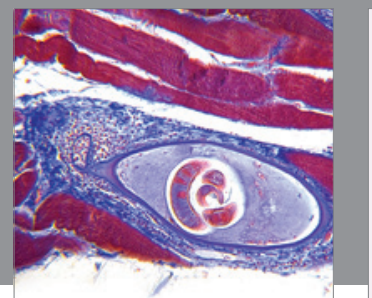

Gastroenterology

Research and Practice
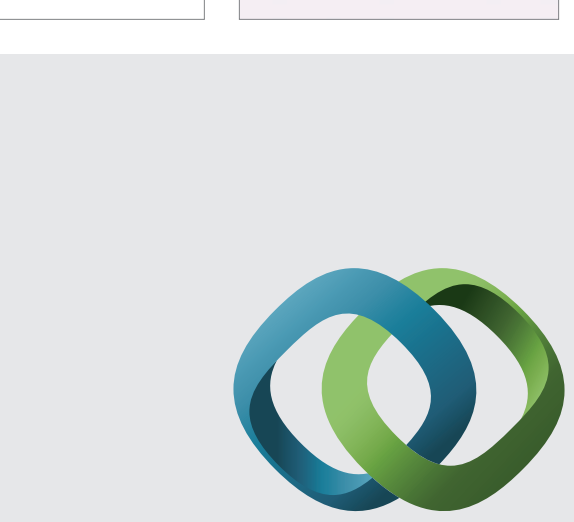

\section{Hindawi}

Submit your manuscripts at

http://www.hindawi.com
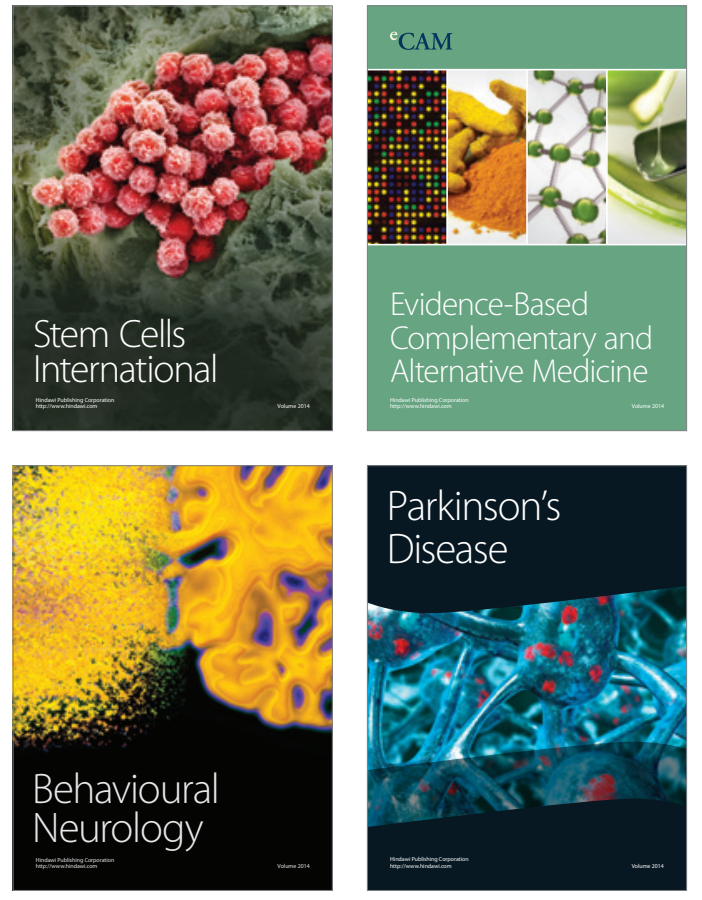
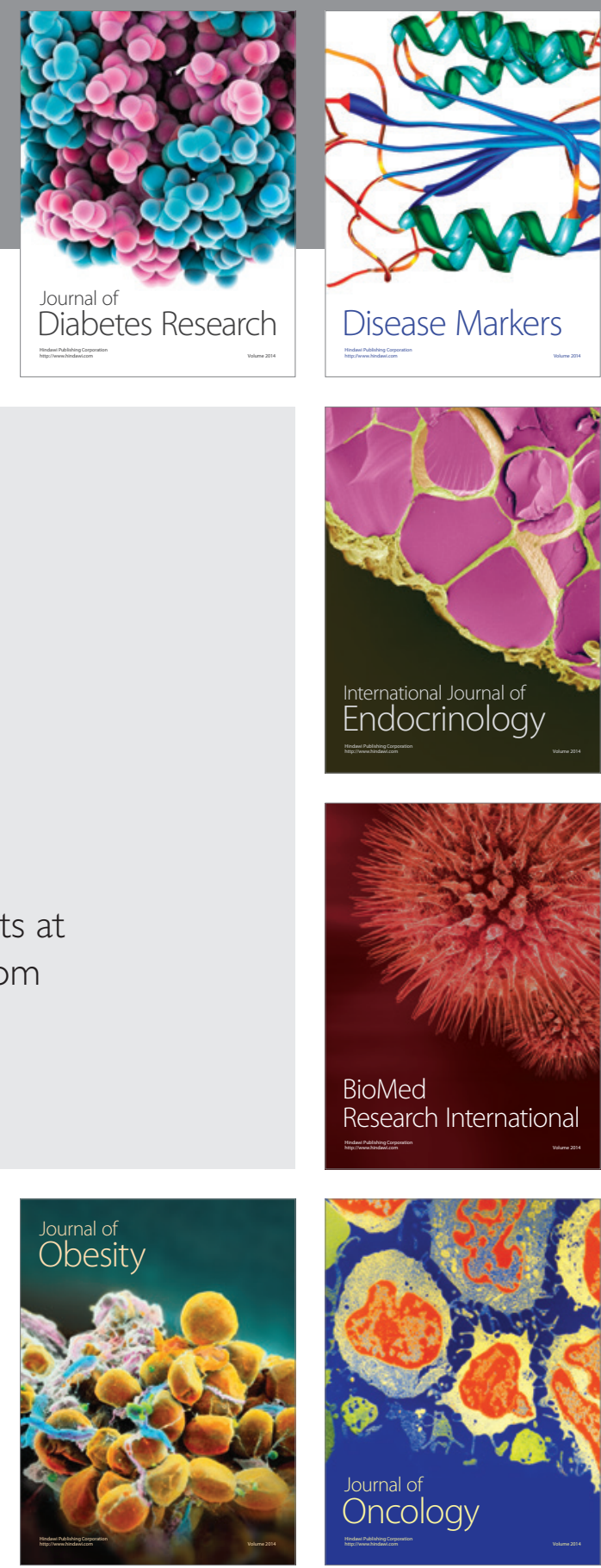

Disease Markers
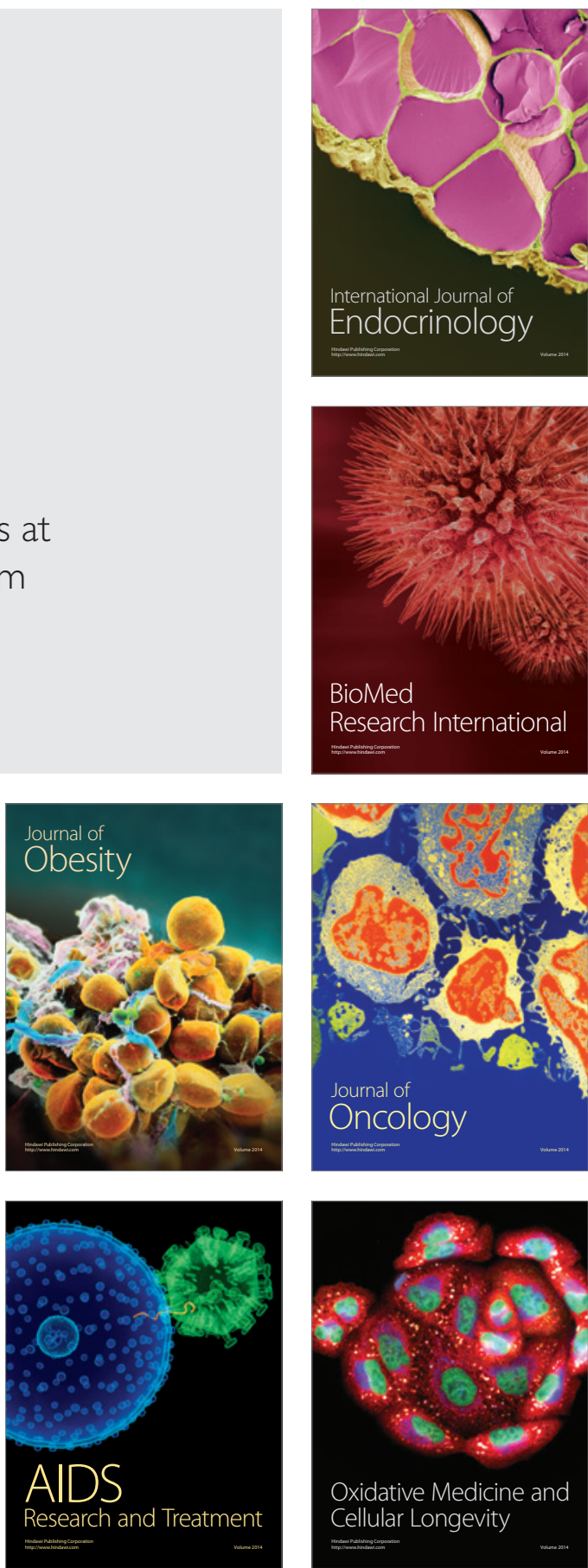